\title{
Web Research Ethics
}

\author{
Confidentiality, Consent, Data Integrity \& More \\ Katharina Kinder-Kurlanda \\ GESIS Leibniz Institute for the Social Sciences \\ Cologne, Germany \\ katharina.kinder-kurlanda@gesis.org \\ Michael Zimmer \\ School of Information Studies \\ University of Wisconsin-Milwaukee \\ Milwaukee, WI USA \\ zimmerm@uwm.edu
}

\begin{abstract}
Researchers studying the web find themselves immersed in a domain where information flows freely but is also potentially bound by contextual norms and expectations, where platforms may oscillate between open and closed information flows, and where data may be user-generated, filtered, algorithmicallyprocessed, or proprietary. When using the internet as a tool or a space of research web scientists are confronted with a continuously expanding set of ethical dilemmas.

Participants of the tutorial will actively engage with concrete example cases of common, not so common, tricky, interesting and puzzling ethical dilemmas. Some in-depth ethical thinking and theory, as well as very practical and creative solutions, will be explored. Participants will also have the chance to bring their own questions or ethical dilemmas to the workshop (it will be possible to 'submit' cases in advance to be discussed in an ethics 'clinic') for discussion and help to find solutions.
\end{abstract}

\section{CCS CONCEPTS}

- Social aspects of security and privacy • Sociology - Privacy policies

\section{KEYWORDS}

Web research ethics, internet research ethics, data ethics, confidentiality, consent, data integrity, privacy

\section{ACM Reference format:}

Kinder-Kurlanda, Katharina and Michael Zimmer. 2019. Web Research Ethics: Confidentiality, Consent, Data Integrity \& More In Proceedings of ACM WebSci '19, fune 30 - fuly 3, 2019, Boston, MA, USA, ACM, NY, NY, USA, 2 pages. https://doi.org/10.1145/3328413.3329797

Permission to make digital or hard copies of part or all of this work for personal or classroom use is granted without fee provided that copies are not made or distributed for profit or commercial advantage and that copies bear this notice and the full citation on the first page. Copyrights for third-party components of this work must be honored. For all other uses, contact the Owner/Author.

WebSci '19 Companion, June 30-fuly 3, 2019, Boston, MA, USA

(c) 2019 Copyright is held by the owner/author(s).

ACM ISBN 978-1-4503-6174-3/19/06.

DOI: https://doi.org/10.1145/3328413.3329797

\section{TUTORIAL DESCRIPTION}

Researchers studying the web find themselves immersed in a domain where information flows freely but is also potentially bound by contextual norms and expectations, where platforms may oscillate between open and closed information flows, and where data may be user-generated, filtered, algorithmicallyprocessed, or proprietary. As individuals increasingly share personal information on platforms with porous and shifting boundaries, the aggregation of data from disparate sources is the norm, and web-based services, and their privacy policies and terms of service statements change too rapidly for an average user to keep up. The ethical frameworks and assumptions traditionally used by researchers and review boards alike are frequently challenged and, in some cases, inadequate.

Researchers using the internet as a tool or a space of research are confronted with a continuously expanding set of ethical dilemmas: What ethical obligations do researchers have to protect the privacy of subjects engaging in activities in "public" internet spaces? Which national or international ethical standards apply when researching global networks, communities, or information flows? How is and should informed consent be obtained online? How should (or should not) research on vulnerable groups, criminal or terrorist organizations or hate speech be conducted? Is deception in online spaces a norm, or a harm? What are researchers' obligations in spaces which are governed by platform providers? Especially if users' and platforms' interests are not aligned? How should we contend with inequalities in data access and uncertainties about data provenance and quality?

In recent years, a growing number of scholars have started to address many of these open questions within this new domain of internet research ethics, focusing on concrete cases and challenges [1-4].

Our goal in this tutorial is to directly engage with these discussions and debates, and to help stimulate new ways to think about - and work towards resolving - the novel ethical dilemmas we face as researchers as web science continues to evolve.

Participants of the tutorial will interactively engage with concrete example cases of common, not so common, tricky, 
interesting and puzzling ethical dilemmas. Some in-depth ethical thinking and theory, as well as very practical and creative solutions, will be explored. Participants will also have the chance to bring their own questions or ethical dilemmas to the workshop (it will be possible to 'submit' cases in advance to be discussed in an ethics 'clinic') for discussion and help to find solutions.

The tutorial is organized by the GESIS Secure Data Center (https://www.gesis.org/en/sdc) which provides secure access to sensitive research data and the PERVADE: Pervasive Data Ethics for Computational Research project (http://pervade.umd.edu/). We thus include European and US perspectives specifically, but the tutorial aims to engage participants from anywhere in the world.

\section{ACKNOWLEDGMENTS}

The work is supported by the National Science Foundation Grant No.: 1704315 "CHS: Large: Collaborative Research: Pervasive Data Ethics for Computational Research.”

\section{REFERENCES}

[1] Clark, K., Duckham, M., Guillemin, M., Hunter, A., McVernon, J., O'Keefe, C., Waycott, J. (2018). Advancing the ethical use of digital data in human research: challenges and strategies to promote ethical practice. Ethics and Information Technology.

[2] Fiesler, C., \& Proferes, N. (2018). "Participant" Perceptions of Twitter Research Ethics. Social Media + Society, 4(1).

[3] Markham, A. N., Tiidenberg, K., \& Herman, A. (2018). Ethics as Methods: Doing Ethics in the Era of Big Data Research-Introduction. Social Media + Society, 4(3)

[4] Zimmer, M., Kinder-Kurlanda, K. (eds.) (2017): Internet Research Ethics for the Social Age: New Cases and Challenges. New York et al.: Peter Lang. 